
\title{
R Research Square \\ Influence of Copper Slag On The Mechanical And Durability Properties of High Strength Concrete
}

Jagan Sivamani ( $\nabla$ s.jagan@klu.ac.in )

Kalasalingam Academy of Research and Education https://orcid.org/0000-0002-4196-7803

\section{Research Article}

Keywords: copper slag, high strength concrete, strength, durability

Posted Date: January 31st, 2022

DOI: https://doi.org/10.21203/rs.3.rs-1187203/v1

License: (9) This work is licensed under a Creative Commons Attribution 4.0 International License. Read Full License 


\section{Abstract}

Excessive consumption of river sand has necessitated the utilization of alternative sustainable materials. Perhaps, slag produced as a by-product during copper extraction was dumped as waste, leading to disposal problems. This study investigates copper slag (CS) as a substitute for river sand in high-strength concrete (HSC). The concrete mixtures were manufactured with $10 \%, 30 \%, 50 \%, 70 \%$, and $100 \%$ of CS to evaluate the mechanical and durability properties at 7 and 28 days. The results indicate that replacing CS above $50 \%$ affects the performance characteristics of the HSC. The strength of HSC with $50 \%$ CS was improved by $5.6 \%$, whereas the strength of HSC with $100 \%$ CS was reduced by $2.75 \%$ at 28 days. However, increased curing to 90 days improved the strength of the former by $7.16 \%$ and reduced the latter by only $0.23 \%$. The water absorption, porosity, and RCPT of the concrete mixtures with $100 \%$ CS were increased by $10.44 \%, 13.20 \%$, and $19.56 \%$ compared to control concrete. The microstructural investigations report the formation of voids in the concrete mixtures with CS beyond the optimum level of replacement.

\section{Introduction}

The production of concrete has been rapidly increasing due to high-rise buildings, bridges, dams, etc. Aggregates are the essential building material used in concrete production, accounting for about 65-70 percent of its total volume. Perhaps, excess utilization of aggregates leads to scarcity in natural resources that necessitate the utilization of industrial waste materials as aggregates in concrete. The alternative wastes from the industries might be used with the criteria that they tend to reduce the exploitation of natural wealth without affecting the concrete's performance. The utilization of industrial and other conventional wastes could overcome the effect of scarcity in construction materials. Many wastes such as steel slag, rice husk ash, coal bottom ash, fly ash, foundry sand, etc., were utilized as a suitable alternative in the concrete. One such derivative recovered during the copper production process is the CS utilized in the concrete. Approximately 2-3 tons of CS will be generated during 1 ton of copper production (Dhir et al. 2017, Bipra et al. 2003, Jarošíková et al. 2017, and Mikoda et al. 2019). In India, around 2500 tons of CS was manufactured every day, for a total annual production of 1.5 to 2 million tons.

For the past few years, pioneering the construction of high-rise buildings, HSC was utilized by the construction engineers due to its better performance characteristics than NSC. The use of HSC has improved in all parts of the world, and it can be found suitably in the construction of bridges, dams, shear walls, foundations, etc.

Numerous researches have been performed with the CS as a viable alternative to cement (Tixier et al. 1997, Perrson 2004) and fine aggregates (Al-Jabri et al. 2009, Alnuaimi 2012, Al-Jabri et al. 2011, Wu et al. 2010) in the concrete. (Al-Jabri et al. 2009) investigated the properties of HSC with CS as a suitable replacement to fine aggregate and observed that concrete with $50 \%$ of CS results in the strength properties equivalent to the control concrete. It is also observed that an increase in the CS increases the 
density and water absorption of the concrete. (Brindha and Nagan 2010) observed that concrete with $40 \%$ of CS show 35-40\% improvement in the compressive strength and 30-35\% improvement in the split tensile strength of the concrete. In addition, the leaching study performed revealed that the CS does not cause any leaching effect of harmful elements, thereby reducing the environmental impact. (Ibrahim et al. 2008) confirmed the latter with a study, where the TCLP and SPLP tests indicate the occurrence of heavy metals that does not possess any environmental hazards. (Khanzadi et al. 2009) investigated the bonding characteristics of the CS and observed an increase in the rebound hammer value from 2.6-9.3\%. This is due to the densified microstructure and superior bond between the CS and the cement matrix. Several additional research (Selvi et al. 2014, Bhoi et al. 2018, Reddy et al. 2016, and Al-Jabri et al. 2006) conclude that complete utilization of CS as river sand affects the properties of concrete to a greater extent. In contrast, studies by (Tiwari et al. 2013, Tokuhashi et al. 2001, Merinkline et al. 2013, Natarajan et al. 2014a, and Natarajan et al. 2014b) indicate that concrete with $100 \%$ of CS as fine aggregate show performance characteristics equivalent to that of the control concrete.

(Lavanya et al. 2013) performed permeability studied on concrete with CS and reported that an increase in the CS increases the permeability of the concrete. (Al-Jabri et al. 2011) revealed that replacing CS over $50 \%$ increases water absorption and hence affecting the other durability characteristics of the concrete. Similar to other studies performed by (Brindha and Nagan 2010; Rajkumar et al. 2015, Velumani and Nirmalkumar 2014) limited the utilization of CS to $40 \%$ to decrease the water absorption rate in the concrete.

In contrast, (Mithun and Narasimhan 2016) observed a decrease in the rate of water absorption in the concrete after complete utilization of the CS. Perhaps, increase in the chloride ingression of the concrete was observed with increase in the water absorption (Pazhani 2010; Rajkumar et al. 2015). (Patnaik et al. 2015, Brindha and Nagan 2010, Priyanka and Thahira 2013) observed that increasing the CS improves the depth of acid penetration in the concrete owing to an increase in pore volume.

Based on the review of various literatures, no optimal level of replacement of CS to fine aggregate was observed as it depends mainly on the $\mathrm{w} / \mathrm{c}$ ratio of the concrete mixes. Furthermore, as CS was replaced for sand, better particle packing of CS may tend to reduce the pore volume, thus improving the concrete's properties. The study on the effect of particle packing of CS on the properties of the concrete is also minimal. Considering these aspects, in this study, the CS collected from the copper industry was presaturated, and the effective particle packing of the CS was ensured before its utilization as fine aggregate in the concrete. In this study, the fine aggregate was replaced by $0 \%, 10 \%, 30 \%, 50 \%, 70 \%$, and $100 \%$ of $\mathrm{CS}$, and the mechanical and durability properties of the concrete were determined. Micro-structural studies such as SEM and XRD was performed to investigate the behaviour of the CS in the HSC.

\section{Methodology}

\section{Materials}


43 grades OPC confirming to IS 4031 - 1988, river sand (RS) passing through $2.36 \mathrm{~mm}$ and retained on $1.18 \mathrm{~mm}$ IS sieve as natural fine aggregate (NFA), gravel of sizes varying from $10 \mathrm{~mm}$ to $20 \mathrm{~mm}$ as natural coarse aggregate (NCA) and potable water was used as the ingredients of concrete for the entire study. Conplast SP430, a naphthalene-based superplasticizer (SP) at a dosage of $0.5 \%$, was used as a superplasticizer for HSC throughout the study. Due to the higher specific gravity of SP (1.24) compared to water, nearly 20 to $25 \%$ of water content was reduced in the preparation of HSC.

\section{Copper slag}

The copper slag (CS) used in this study was collected from the Sterlite copper industry, thoothukudi, India. The CS collected from the industry is an air-cooled granular slag. The CS exhibit low $\mathrm{CaO}$ concentration and a high $\mathrm{SiO}_{2}(33.07 \%), \mathrm{Al}_{2} \mathrm{O}_{3}(2.63 \%)$, and $\mathrm{Fe}_{2} \mathrm{O}_{3}(54.12 \%)$ making it ideal for the substitution of fine aggregate in the concrete. Also, the total of three oxides is nearly $90 \%$ that exceeding the requirement of $70 \%$ as recommended by ASTM C618-99. The properties of CS as mentioned in Table 1 depend on the porous structure and the degree of grinding to condense the slag to a fine powder. The CS possess traces of heavy metals like arsenic, chromium, copper, zinc, lead, nickel, and iron in stable condition that does not leach under normal environmental conditions (SERC, 2010). Also, the leaching of heavy metals in CS under aggressive environmental conditions was well below the toxicity level. The effective particle size distribution of CS and RS is shown in Figure 1.

Table 1

Physical properties of copper slag

\begin{tabular}{|ll|}
\hline Property & Copper Slag \\
\hline Specific gravity & 3.75 \\
\hline Density $\left(\mathrm{kg} / \mathrm{m}^{3}\right)$ & 1894 \\
\hline Water absorption $(\%)$ & 0.32 \\
\hline Fineness modulus & 3.28 \\
\hline
\end{tabular}

\section{Concrete mix, specimen preparation, test methods}

IS 10262:2009 method of mix design was carried to prepare the HSC mixes of 1: 1.47: 3.04: 0.4. The concrete mixtures prepared with OPC, river sand, and natural gravel was categorized as normal aggregate concrete (NAC). The concrete mixtures prepared with $10 \%, 30 \%, 50 \%, 70 \%$ and $100 \%$ of CS were categorized as copper slag concrete (CSC). The concrete mixes were prepared, and the fresh mix was tested for its workability properties as per IS 1199 (1959). The prepared concrete mixtures were fabricated into the concrete cube of $150 \mathrm{~mm}$ to evaluate its compressive strength as per ASTM C39/C39-20, cylinders of $150 \mathrm{~mm} \times 300 \mathrm{~mm}$ to evaluate its split tensile strength as per ASTM C469/C469M - 17 and prisms of $500 \mathrm{~mm} \times 100 \mathrm{~mm} \times 100 \mathrm{~mm}$ to evaluate its flexural strength as per ASTM C 78. The rate of concrete water absorption was determined at 56 days with $150 \mathrm{~mm}$ cubes as per ASTMC642-13 (2013). 
The initial water absorption rate was determined with $150 \mathrm{~mm}$ cubes as per BS 1881 -208 (1996). The rate of ingression of chloride ions through the concrete was performed at 28 days with $100 \mathrm{~mm} \times 200$ $\mathrm{mm}$ cylindrical discs as per ASTM C1202. The experiments were done in triplets to determine the average value.

\section{Experimental Results \\ Characterization of materials}

Figure 2 shows the CS and RS used in the entire study. The CS was found to be more angular than RS due to the smelting process of the copper. From the results of physical properties and chemical composition, it is found that the percentage of $\mathrm{CaO}$ in $\mathrm{CS}$ is low compared to OPC, which indicates the lower cementitious property of $\mathrm{CS}$, perhaps the percentages of $\mathrm{SiO}_{2}, \mathrm{Fe}_{2} \mathrm{O}_{3}$, and $\mathrm{Al}_{2} \mathrm{O}_{3}$ are more that recommends the possibility of utilization of CS as an alternative for sand in the concrete because of its higher pozzolanic activity. The XRD images of RS and CS are shown in Figure 3. The highest peak in the XRD pattern of RS was found to be $\mathrm{SiO}_{2}$, and that could be favourable in the formation of C-S-H. For CS, the highest peak was observed with $\mathrm{Fe}_{2} \mathrm{O}_{3}$ and $\mathrm{SiO}_{2}$ with the former resulting from the production of copper, and the latter promote the formation of C-S-H gel. Figure 4 shows the SEM images of RS and CS. The SEM images indicate higher angularity and sphericity of CS, which implies the possible replacement of CS to RS in the concrete.

\section{Workability}

The slump values of NAC and CSC are shown in Figure 5. The slump of the CSC increases with an increase in the percentage of CS. The slump of the NAC was found to be $31 \mathrm{~mm}$, and the CSC - 100 was found to be $39 \mathrm{~mm}$. This is due to the low rate of absorption of water characteristics of CS compared to RS. The excess unreacted water remains in the concrete mix after hydration results in the segregation and bleeding of the concrete mixes and hence affecting the workability of HSC (Selvi et al. 2014, Bhoi et al. 2018).

\section{Density}

Figure 6 shows the density of NAC and CSC at 28 days. The density of the CSC increases as the fractions of the CS increases. The density of NAC was $2560 \mathrm{~kg} / \mathrm{m}^{3}$, but the density of CSC - 10 was $2572 \mathrm{~kg} / \mathrm{m}^{3}$, which was determined to be $0.46 \%$ higher than NAC. CSC - 50 has a density of $2654 \mathrm{~kg} / \mathrm{m}^{3}$ and is determined to be $3.54 \%$ higher than NAC. Similarly, the density of CSC -100 was $2740 \mathrm{~kg} / \mathrm{m}^{3}$, which was determined to be $6.56 \%$ higher than NAC. The results show an increase in concrete density with an increase in CS replacement due to the higher specific gravity of the CS particles.

\section{Compressive strength}


Figure 7 shows the compressive strength of NAC and CSC mixes. The compressive strength of the CSC decreases with an increase in the percentage of CS. The optimal replacement of CS was observed to $50 \%$, beyond which it decreases irrespective of the curing period. The compressive strength of CSC - 10, CSC - 30, and CS - 50 was $1.35 \%, 3.88 \%$, and $5.61 \%$ more than NAC at 28 days and $2.14 \%, 4.29 \% 7.16 \%$ more compared to NAC at 90 days. The improved compressive strength is attributable to the surface roughness of CS, which has a lower water absorption capacity than RS (Bhoi et al. 2018, Al Jabri et al. 2011). However, the compressive strength of CSC -100 was $3.05 \%$ and $0.25 \%$ less compared to NAC at 28 days and 90 days. Due to reduced water absorption at higher replacements of CS, excess water remains in the mix, resulting in increased porosity and consequently lowering the compressive strength of the concrete (Maharishi et al. 2020, Ushakranti et al. 2020).

\section{Split tensile strength}

Figure 8 shows the split tensile strength of the NAC and CSC mixes. The split tensile strength varies in the same pattern of the compressive strength at different replacements of CS. The tensile strength of CSC 10, CSC -30 , CS -50 was $0.61 \%, 2 \%, 2.78 \%$ and $0.98 \%, 2.14 \%$ and $3.46 \%$ higher compared to NAC at 28 and 90 days. However, the tensile strength of CSC -100 was $3 \%$ and $0.25 \%$ lower than NAC at 28 and 90 days, respectively. This is due to a decrease in the water absorption rate of the CS, which results in larger porosity of the concrete mixes with higher replacement rates (Al Jabri et al. 2009, Wu et al. 2010).

\section{Flexural strength}

Figure 9 shows the flexural strength of NAC and CSC mixes. Beyond $50 \%$ replacement of CS in HSC, the flexural strength of the CSC also decreases. At 28 and 90 days, the flexural strength of CSC - 10, CSC 30 , and CSC - 50 was $0.59 \%, 1.91 \%, 2.77 \%$ and $1.01 \%, 2.78 \%, 3.76 \%$ higher than NAC. Nonetheless, the flexural strength of CSC - 100 was $1.51 \%$ and $0.43 \%$ lower than that of NAC after 28 and 90 days, respectively. Because of the increased porosity of the concrete mixes, the variation in flexural strength of $\mathrm{CSC}$ is similar to that of compressive strength and split tensile strength.

\section{Durability Characteristics}

The behavior of CS on the durability characteristics of NAC and CSC was evaluated by performing water absorption, sorptivity, porosity, and RCPT tests. The durability characteristics of the concrete mixtures at 56 days are shown in Table 2. The mixes such as CSC - 10, CSC - 30, and CSC - 50 had lower porosity than NAC by $10.43 \%, 17.95 \%$ and $28.59 \%$, respectively. The decrease in the pore volume of the concrete was effectively imitated by the decrease in the concrete's water absorption. Thus, the water absorption of CSC -10, CSC -30 , and CSC - 50 was $2.24 \%, 13.04 \%$ and $14.34 \%$ lower than NAC. Such variations in water absorption and porosity were due to the glossy surface texture of the CS particles. Higher replacement of such CS particles eventually increases the water absorption and porosity of the concrete mixes. For instance, at 56 days, the porosity of CSC - 70 and CSC -100 was $10.44 \%$ and $13.20 \%$ greater than NAC. 
Table 2

Durability properties

\begin{tabular}{|lllll|}
\hline Mix ID & Water absorption (\%) & Porosity (\%) & Sorptivity (mm/hr) & RCPT (Coulombs) \\
\hline NAC & 2.23 & 10.25 & 0.21 & 1850 \\
\hline CSC - 10 & 2.18 & 9.18 & 0.17 & 1600 \\
\hline CSC - 30 & 1.94 & 8.41 & 0.17 & 1400 \\
\hline CSC - 50 & 1.91 & 7.32 & 0.13 & 1200 \\
\hline CSC - 70 & 2.37 & 10.63 & 0.31 & 2150 \\
\hline CSC - 100 & 2.49 & 11.81 & 0.43 & 2300 \\
\hline
\end{tabular}

Similarly, the rate of absorption of water of CSC - 70 and CSC - 100 was $5.91 \%$ and $10.44 \%$ higher than NAC. Because of the substandard water absorption characteristics of CS, excess mixing water remains in the concrete, resulting in the formation of voids (Prabhat et al. 2018, Bhoi et al. 2018). Similar behavior of CS was observed concerning sorptivity also. The sorptivity of CSC - 10, CSC - 30, and CSC - 50 was $19.04 \%, 19.01 \%$, and $38.09 \%$ less than NAC. Perhaps, the sorptivity of CSC -70 and CSC -100 was $32.25 \%$ and $51.16 \%$ more compared to NAC. The indirect measure of chloride intrusion into the concrete mixtures depends on the pore volume of the concrete. The RCPT of CSC - 10, CSC - 30, and CSC - 50 was $13.51 \%, 24.32 \%$, and $35.13 \%$ less than NAC. The lower absorption characteristics and higher angularity of CS result in the formation of concrete microstructure with less pore volume, thus reducing the RCPT values. However, the RCPT of CSC - 70 and CSC - 100 was $13.95 \%$ and $19.56 \%$ higher than NAC. The RCPT values increases as the pore volume increases, which is followed by an increase in the proportion of CS particles. (Prabhat et al. 2018, Mithun and Narasimhan, 2016).

\section{Discussions}

The prime objective of the research is to evaluate the viability of CS as an alternative to RS and to optimise the percentage of CS in the HSC. The former objective was established by performing physical property studies to confirm its suitability as a replacement to RS in the concrete. The latter objective was established by evaluating the hardened properties with different percentages of CS in the HSC. In addition, durability studies were performed to assess the performance of HSC with different percentage of CS in comparison to NAC. The justification to the above studies was also validated through microstructure studies performed using SEM.

The CS used as an alternative to RS can be studied for its suitability in the concrete by evaluating its physical properties and chemical characteristics. From the oxide composition of the CS, the percentage of $\mathrm{CaO}$ is significantly less (6\%), indicating its incompatibility as a cement replacement in the concrete. However, the percentages of $\mathrm{SiO}_{2}(25 \%)$ and $\mathrm{Fe}_{2} \mathrm{O}_{3}(35 \%)$ in $\mathrm{CS}$ were very high, confirming their suitability for RS replacement. In addition, other physical properties of CS were equivalent to RS, excepting water 
absorption. The lower water absorption characteristics of CS results in the increased free water content with an increase in the replacement of CS, consequently leading to an improvement in the workability of the concrete. From Table 1, the specific gravity of CS (3.75) is increased by $26.9 \%$ compared to that of river sand (2.74). The increased density of concrete is accompanied by the increase in the specific gravity of CS particles due to the angular texture of CS particles. In addition, a study performed by (Al Jabri et al. 2011) infers that the source and the age of river sand have detrimental physical properties compared to that of the CS. As we know, the natural formation of RS is accompanied by the weathering process that occurs over the years wherein the abrasion properties get weakened, causing the RS to lose its angular texture. This, in turn, provides recommendations over the use of CS as a viable alternative to the RS.

The workability of the CSC increases with the increase in the percentage of CS due to its polished surface texture and lower absorption characteristics (Hwang 1989). The reduced water absorption characteristics of CS tend to leave excess free water content in the concrete mixture even after hydration (Al Jabri et al. 2009, Ayano et al. 2000). In addition, effective particle packing of CS with river sand and the addition of SP increased the workability of the concrete even at a lower w/c ratio (Wu et al. 2010, Al Jabri et al. 2009).

The influence of different proportions of CS on the strength of the CSC at 7, 28, and 90 days was studied. The concrete mixtures with $0,10,30,50,70$, and 100 percent of CS were prepared for investigation at a $0.4 \mathrm{w} / \mathrm{c}$ ratio. The minimum strength of concrete was observed as $65.67 \mathrm{MPa}$ at 28 days and $70.91 \mathrm{MPa}$ at 90 days. However, it is observed that the strength of the CSC increases as the rate of the curing period increases. The strength of the CS - 100 was reduced by $3.18,3.05$, and 0.23 percent at 7,28 , and 90 days, respectively. The maximum strength was recorded as $76.57 \mathrm{MPa}$ for CSC - 50 at 90 days. The effective particle packing nature of CS with river sand due to its angularity tend to reduce the void formation enabling the development of a strong interfacial transition zone between the matrix and the NCA and thus to improve the hardened properties of the CSC (Cheong et al. 2007, Khanzadi et al. 2009, Al Jabri et al. 2009). At higher percentages of CS, the formed excess free water content remains unreacted, resulting in the formation of capillary voids, reducing the strength of the concrete (Caliskan and Behnood 2004, Wu et al. 2010, Al Jabri et al. 2009). Also, it could be observed that for HSC, the strength CS - 100 was nearly equal to that of the NAC. This is because the excess free water content causing bleeding in the concrete mixture was detained by the addition of superplasticizers without affecting the workability of the concrete.

From the test results, the optimal replacement of CS was observed to be $50 \%$. In addition to strength, tests to evaluate the durability properties of the concrete, such as water absorption, porosity, and RCPT, were performed. The initial water absorption rate at 10 minutes reduces with an increase in the CS up to $50 \%$. The better interlocking property of CS with cement matrix and aggregates results in the densification of concrete microstructure with fewer voids. Beyond $50 \%$, the uptake of water by the concrete increases rapidly. The maximum uptake of $0.42 \mathrm{ml} / \mathrm{m}^{2}$.s for HSC with complete utilization of CS was observed. Such excess water uptake by the concrete mixes is due to capillary voids in the hardened concrete. The results of the initial water absorption rate were quite reflective of the results of saturated water 
absorption. The maximum water absorption recorded at 56 days was $2.49 \%$, with $100 \%$ utilization of CS. The test results show a decline in the water absorption with an increase in the CS up to $50 \%$, beyond which an increasing trend was observed. For HSC, the initial rate of water absorption and saturated water absorption was quite below the limitation because the addition of superplasticizers seized excess free water content promoting bleeding in the concrete. As we know, increased void content will tend to increase the rate of charge passing through the concrete mixes. The decreased resistance to chloride ions was observed in the CS - 100, and the increased resistance was with the CS - 50. The results obtained were similar to (Saraswathy et al. 2014, Rajasekar et al. 2019).

The SEM images (Figure 10) show the microstructure of the concrete mixes with different replacement levels of CS. Figure 10 (a) shows the microstructure of the NAC. Figure 10 (b) shows the microstructure of CSC - 50. Figure 10 (c) shows the microstructure of the CSC - 100. The SEM image of the CSC - 50 shows dense concrete micro-structure magnified at $200 \mu \mathrm{m}$. No evident micro-pores were perceived in the NAC and CS - 50. The higher angularity and better compressibility of CS result in reduced pore volume in the concrete microstructure, thus improving the concrete's strength compared to other mixes. However, the SEM image of CSC - 100 shows more micro-pores resulting from the higher replacement of CS in the concrete. The interconnectivity of such pores forms the weak link in the concrete microstructure and thus results in deprived mechanical and durability properties.

\section{Conclusions}

The utilization of CS as a viable replacement to river sand was investigated and based on the experimental results, the research provides suitable conclusions as follows:-

1. The water absorption of CS is lower than that of RS due to its glassy surface texture.

2. The workability of the HSC increases with the increase in the percentage of CS owing to the reduced water absorption characteristics of CS.

3. The optimal replacement of CS in the HSC was found to be $50 \%$. The concrete mix CSC - 50 shows a $5.61 \%, 2.75 \%$, and $2.78 \%$ increase in the compression, tension, and flexure compared to NAC at 28 days. Similarly, the CSC - 50 shows a $7.16 \%, 3.46 \%$, and $3.76 \%$ increase in compression, tension, and flexure compared to NAC at 90 days.

4. The absorption rate of water and pore volume of CSC - 50 was $14.34 \%$ and $48.09 \%$ low compared to NAC at 56 days. Though, the rate of absorption of water and pore volume of CSC -100 was $10.44 \%$ and $9.37 \%$ high compared to NAC at 56 days.

5. The initial surface of the concrete at the first 10 minutes increases beyond $50 \%$ replacement of CS in the concrete.

6. The rate of permeation of chloride ions into the concrete is directly dependent on the pore volume of the concrete. The concrete mix CSC - 100 reveal higher chloride ion penetration compared to CSC - 50 
and NAC.

The research concludes the viability of using copper slag as a suitable alternative to the river sand in the concrete. The results indicate that $50 \%$ utilization of copper slag will improve the properties of the concrete. Besides, a higher curing period improves the copper slag concrete's hardened and durability properties that are comparable to NAC. This could pave the way for the scarcity of river sand in the construction and disposal problems of copper slag.

\section{Declarations}

\section{Funding}

The author declares that no funds, grants, or other support were received during the preparation of this manuscript.

\section{Conflicts of Interest}

The authors declare no conflicts of interest

\section{Author's information}

\section{$\underline{\text { Affiliations }}$}

Faculty, Department of Civil Engineering, Kalasalingam Academy of Research and Education, Anand Nagar, Krishnankoil, 626 126, Tamilnadu, India

Jagan Sivamani

\section{Contributions}

Jagan Sivamani - Collection of data, methodology, conduct of experiments, analysis of data, article writing

\section{Ethics declaration}

Ethics approval and consent to participate - Not applicable

Consent for publication - Not applicable

Competing interests - The authors declare no competing interest.

Availability of data and materials - Not applicable

\section{References}


1. Al-Jabri, K. S. (2006). “Copper slag as fine aggregate in high-performance concrete." Highperformance structures and materials III. WIT Transactions on the Built Environment, 85, 381-389.

2. Al-Jabri, K. S., Al-Saidy, A. H., Taha, R. (2011). "Effect of copper slag as a fine aggregate on the properties of cement mortars and concrete." Construction and Building Materials, 25, 933-938.

3. Al-Jabri, K. S., Hisada, M., Al-Oraimi, S. K., Al-Saidy, A. H. (2009). “Copper slag as sand replacement for high performance concrete." Cement and Concrete Composites, 31, 483-488.

4. Alnuaimi, A. S. (2012). "Effects of copper slag as a replacement for fine aggregate on the behavior and ultimate strength of reinforced concrete slender columns." Journal of Engineering Research, 9, 90-102.

5. ASTM C1202-19, Standard Test Method for Electrical Indication of Concrete's Ability to Resist Chloride Ion Penetration, ASTM International, West Conshohocken, PA, 2019, www.astm.org

6. ASTM C39 / C39M-21, Standard Test Method for Compressive Strength of Cylindrical Concrete Specimens, ASTM International, West Conshohocken, PA, 2021, www.astm.org

7. ASTM C469 / C469M-14e1, Standard Test Method for Static Modulus of Elasticity and Poisson's Ratio of Concrete in Compression, ASTM International, West Conshohocken, PA, 2014, www.astm.org

8. ASTM C618, Standard Specification for Coal Fly Ash and Raw or Calcined Natural Pozzolans for Use in Concrete, ASTM International, West Conshohocken, PA, 2021, www.astm.org

9. ASTM C642-13, Standard Test Method for Density, Absorption, and Voids in Hardened Concrete, ASTM International, West Conshohocken, PA, 2013, www.astm.org

10. ASTM C78 / C78M-21, Standard Test Method for Flexural Strength of Concrete (Using Simple Beam with Third-Point Loading), ASTM International, West Conshohocken, PA, 2021, www.astm.org

11. Ayano, T., Sakata, K. (2000). "Durability of concrete with copper slag fine aggregate." In: Proceedings of the 5th CANMET/ACI International Conference on Durability of Concrete, SP-192, Barcelona, Spain, 141-158.

12. Bhoi, A. M., Yogesh, D. P., Hemant, S. P., Madhav, P. K. (2018). “Feasibility Assessment of Incorporating Copper Slag as a Sand Substitute to Attain Sustainable Production Perspective in Concrete." Advances in Materials Science and Engineering, Volume 2018, 6502890.

13. Brindha, D., Nagan, S. (2010). "Utilization of copper slag as partial replacement of fine aggregate in concrete." IJESE, 3, 579-585.

14. BS 1881-208, Initial rate of absorption of concrete mixtures, British Standards, London, UK, 1996.

15. Caliskan, S., Behnood, A. (2004). "Recycling copper slag as coarse aggregate: Hardened properties of concrete." Proceedings of 7th International Conference on Concrete Technology in Developing Countries, Kuala Lumpur, Malaysia: 91-98.

16. Cheong, C. P., Cheng, C. S., Phuong, P. H. (2007). “Copper slag as fine aggregate substitute in concrete." Civil Engineering Research, 20, 26-29. 
17. Gorai, B., Jana, R. K., Premchand. (2003). “Characteristics and utilization of copper slag-a review." Resources, Conservation and Recycling, 39, 299-313.

18. Hwang, C. L., Laiw, J. C. (1989). "Properties of concrete using copper slag as a substitute for fine aggregate." In: Proceedings of the 3rd International Conference on Fly Ash, Silica Fume, Slag, and Natural Pozzolans in Concrete, SP 114-82, Trondheim, Norway, 1677-1695.

19. Ibrahim, A., Haci, D. (2008). "Utilization of Flotation Wastes of Copper Slag as Raw Material in Cement Production." Journal of hazardous materials, 159, 390-395.

20. IS 10262, Specifications for concrete mix design, Bureau of Indian standards, New Delhi, India, 2009.

21. IS 1199, Slump test of fresh concrete mixture, Bureau of Indian standards, New Delhi, India, 1959.

22. IS 4031, Method of physical tests of hydraulic cement, Bureau of Indian standards, New Delhi, India, 1988.

23. Jarošíková, V., Ettler, M., Mihaljevič, B., Kříbek. (2017). "The pH-dependent leaching behavior of slags from various stages of a copper smelting process: environmental implications." J. Environ. Management, 187,178-186.

24. Khanzadi, M., Behnood, A. (2009). "Mechanical properties of high-strength concrete incorporating copper slag as coarse aggregate." Construction and Building Materials, 23, 2183-2188.

25. Lavanya, C., Rao, A. S., Kumar, N. D. (2013). "Influence of admixtures on load: Settlement behaviour of copper slag: Cushioned expansive soil bed." In Proc., Indian Geotechnical Conference, Indian Geotechnical Society, Roorkee, India

26. Madheswaran, C. K., Ambily, P. S., Dattatreya, J. K., Rajamane, N. P. (2014). “Studies on use of copper slag as replacement material for river sand in building construction." Journal of the Institution of Engineers (India): Series A, 95, 169-177.

27. Maharishi, A., Singh, S. P., Gupta, L. K., Shehnazdeep. (2021). "Strength and durability studies on slag cement concrete made with copper slag as fine aggregates." Materials today proceedings, 38, 26392648.

28. Merinkline, H.H., Devi, S. M., Christy, C. F. (2013). "Fresh and hardened Properties of fly ash based Geopolymer concrete with copper slag." IJERT 2, 1-7.

29. Mikoda, B., Potysz, A., Kmiecik, E. (2019). "Bacterial leaching of critical metal values from Polish copper metallurgical slags using Acidithiobacillus thiooxidans." Journal of Environmental Management, 236, 436-445.

30. Mithun, B. M., Narasimhan, M. C. (2016). "Performance of alkali activated slag concrete mixes incorporating copper slag as fine aggregate." Journal of Cleaner Production, 112, 837-844.

31. Natarajan, M. C., Chandan, G. N., Rajeeth, T. J. (2014a). "Concrete mix design using copper slag as fine aggregate." International Journal of Civil Engineering and Technology, 5, 90-99.

32. Natarajan, M.C., Chandan, G. N., Rajeeth, T. J. (2014b). "Flow properties of cement mortar using copper slag as fine aggregate." Journal of Civil Engineering Technology and Research, 2, 23-31. 
33. Patnaik, B., Seshadri, S. T., Srinivasa, R. (2015). "Strength and durability properties of copper slag admixed concrete." IJRET 4, 158-166.

34. Pazhani, K. C. (2010). "Study on the mechanical properties of copper slag concrete." Engineering Today, 12, 33-44.

35. Perrson, B. (2004). "Fire resistance of self-compacting concrete." Materials and structures, 37, 575584.

36. Prabhat, R. P., Verma, M., Ambily, P. S. (2018). "Sustainable cleaner production of concrete with high volume copper slag." 193, 43-58.

37. Priyanka, K. R., Thahira, M. U. (2013). “Experimental Studies on High Performance Concrete Using Waste Materials." Rural Technology Centre, India. Internal Report, 65 pp.

38. Rajasekar, K., Arunachalam, M., Kottaisamy. (2019). "Assessment of strength and durability characteristics of copper slag incorporated ultrahigh strength concrete." Journal of Cleaner Production, 208, 402-414.

39. Rajkumar, R., Akkineni, S. T., Pandia, R. R. (2015). “Experimental investigation on the mechanical and durability properties of concrete using metakaolin and copper slag." IRJET, 2, 678-685.

40. Ravindra, K. D, Brito, J. D., Mangabhai, R., Lye, Q. C. (2017). “Sustainable Construction Materials: Copper Slag." Wood head Publishing, 2017, https://doi.org/10.1016/C2015-0-00465-8

41. Reddy, M. S., Dinakar, P., Rao, B. H. (2016). "A review of the influence of source material's oxide composition on the compressive strength of Geopolymer concrete." Microporous Mesoporous Materials, 234, 12-23.

42. Saraswathy, V., Karthick, S., Muralidharan, S. (2014). "Corrosion and leaching studies in blended copper slag mortar." Journal of Engineering and Technology, 4, 29-37.

43. Selvi, P., Narayani, P., Ramya, G. (2014). "Experimental Study on Concrete Using Copper Slag as Replacement Material of Fine Aggregate." Journal of Civil and Environmental Engineering, 4, 100056.

44. Tiwari, A.K., Bhattacharya, A. (2013). "Use of copper and granulated blast furnace slag as fine aggregate." In: Proceedings of the International Conference on Innovation in Concrete, Hyderabad, India, 320-329.

45. Tixier, R. R., Devaguptapu, B., Mobasher. (1997). "The effect of copper slag on the hydration and mechanical properties of cementitious mixtures." Cement and Concrete Research, 27, 1569-1580.

46. Tokuhashi, K., Shoya, M., Aba, M., Sugita, S. (2001). "Application of slag fine aggregates to produce self-compacting concrete." In: Proceedings of 26th Conference on Our World in Concrete \& Structures, Singapore, 649-656.

47. Usha Kranti, J., Naga Sai, A., Rama Krishna, A., Srinivasu, K. (2021). "An experimental investigation on effect of durability on strength properties of M40 grade concrete with partial replacement of sand with copper slag." Materials today proceedings, 43, 1626-1633. 
48. Velumani, M., Nirmalkumar, K. (2014). “Durability and characteristics of copper slag as fine aggregate and fly ash as cement on concrete." In: Proceedings of 2nd International Conference on Current Trends in Engineering and Technology, Coimbatore, India, 222-227.

49. Wu, W., Zhang, W. Ma, G. (2010). "Optimum content of copper slag as a fine aggregate in high strength concrete." Material design, 31, 2878- 2883.

\section{Figures}

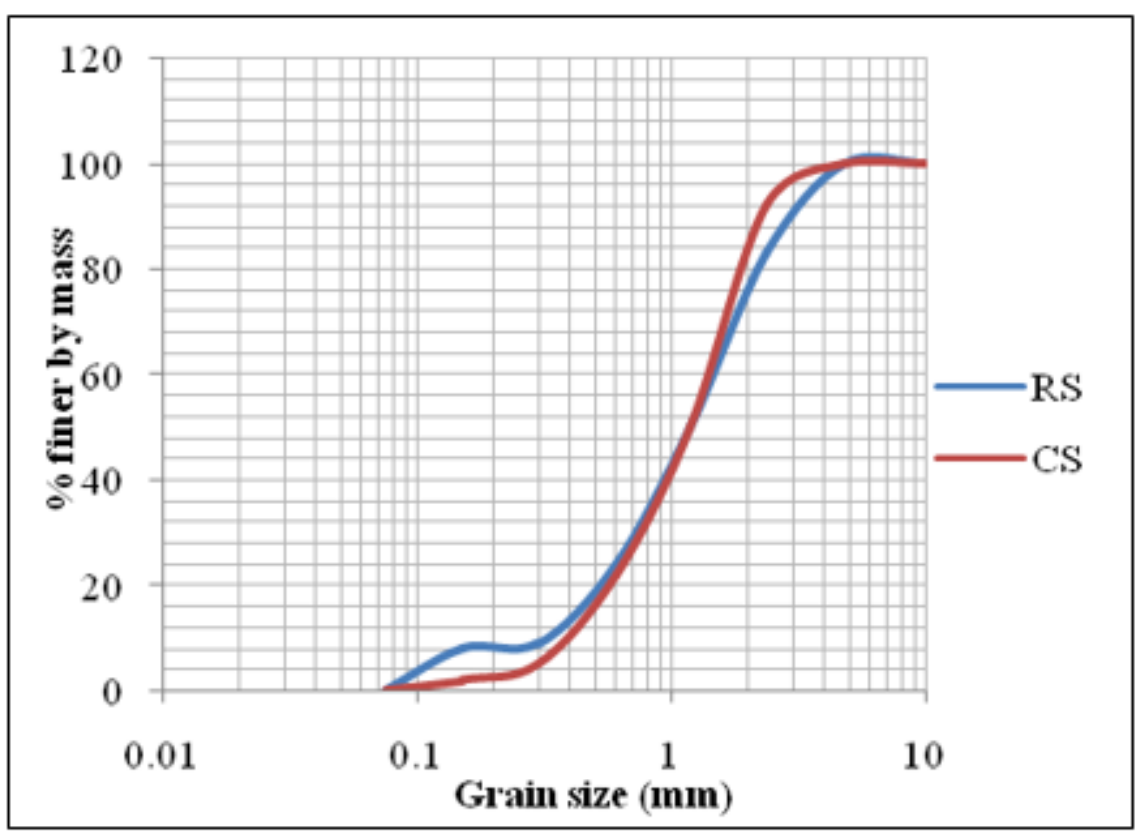

Figure 1

Gradation curves of RS and CS 

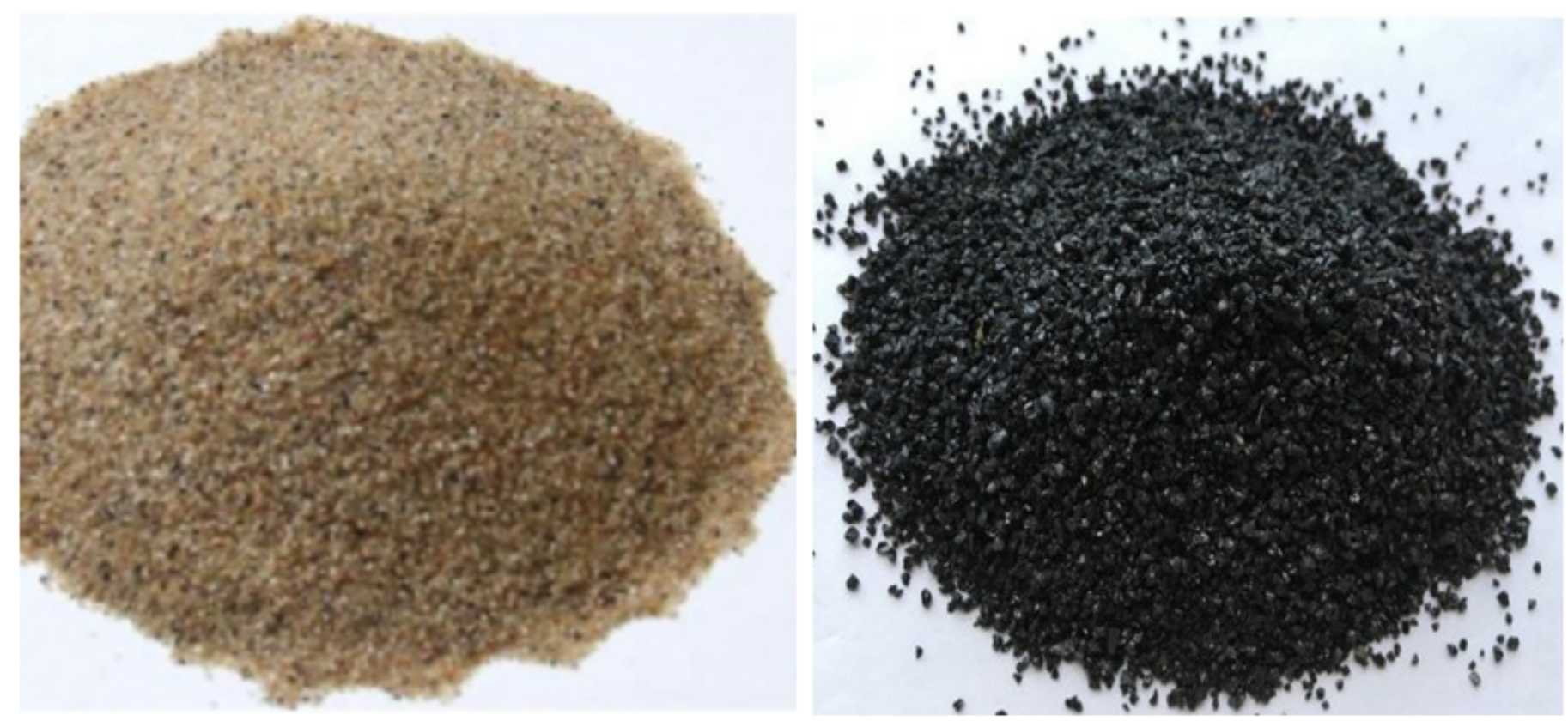

Figure 2

Visual observation (a) RS (b) CS
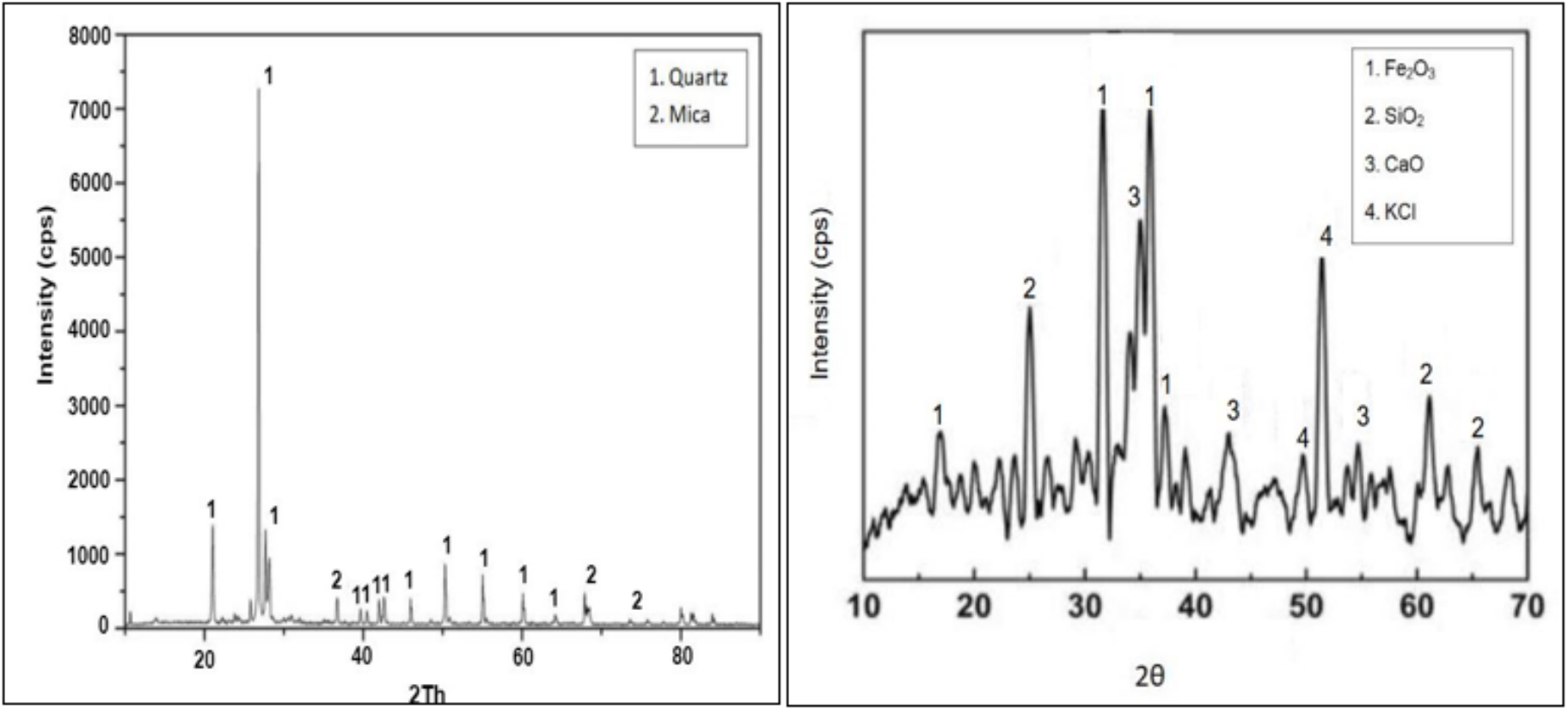

Figure 3

XRD patterns (a) RS (b) CS 


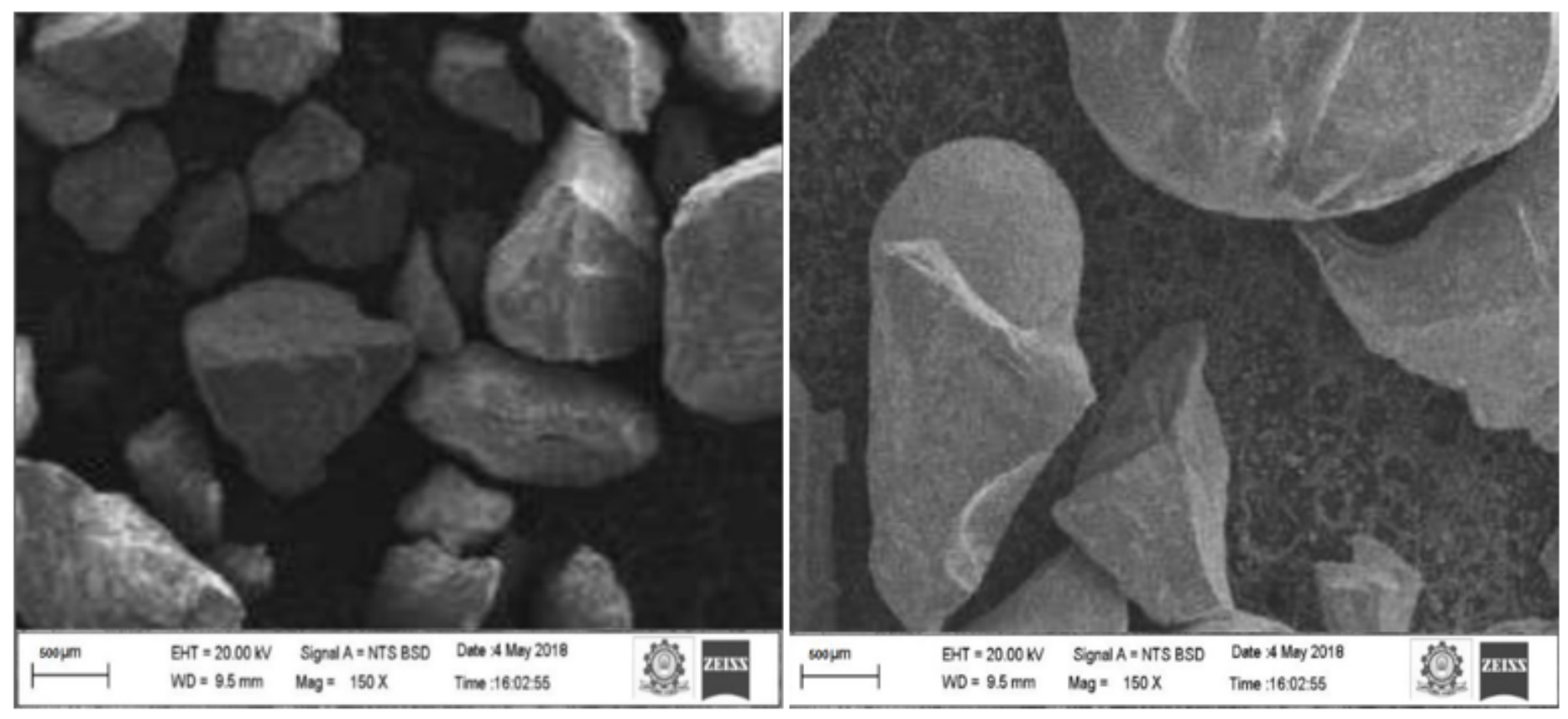

Figure 4

SEM images (a) RS (b) CS

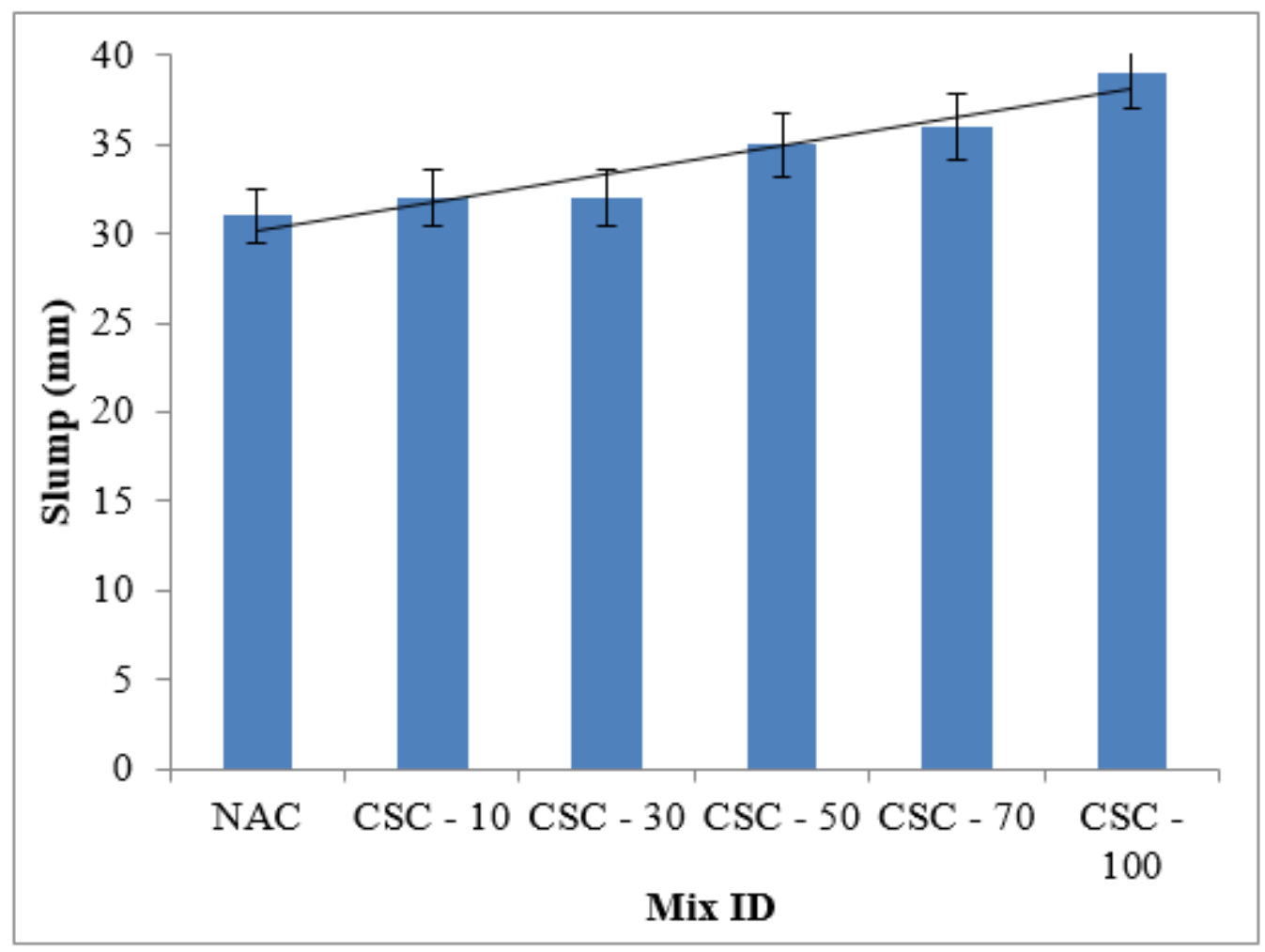

Figure 5

Slump of concrete mixes 


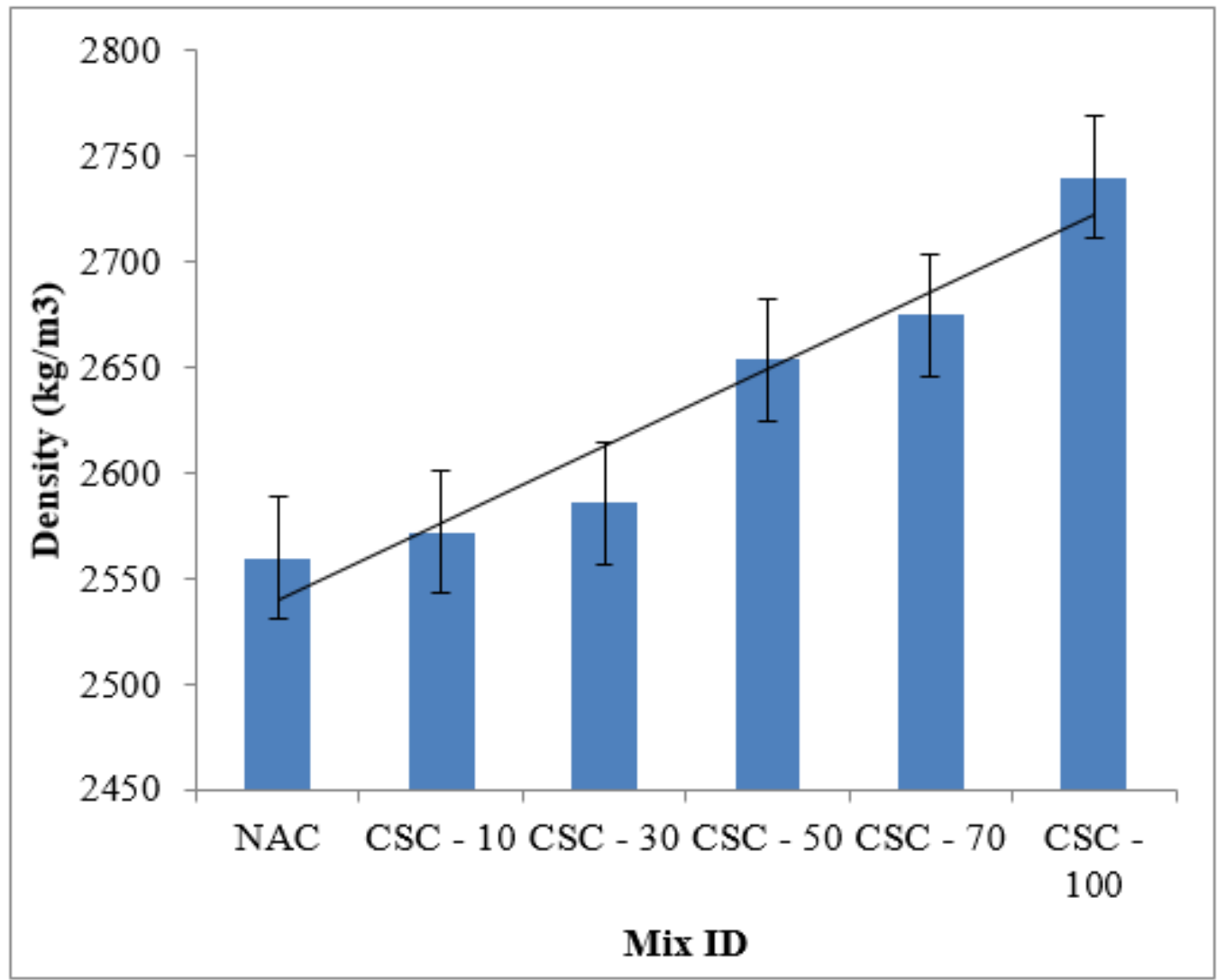

Figure 6

Density of concrete mixes 


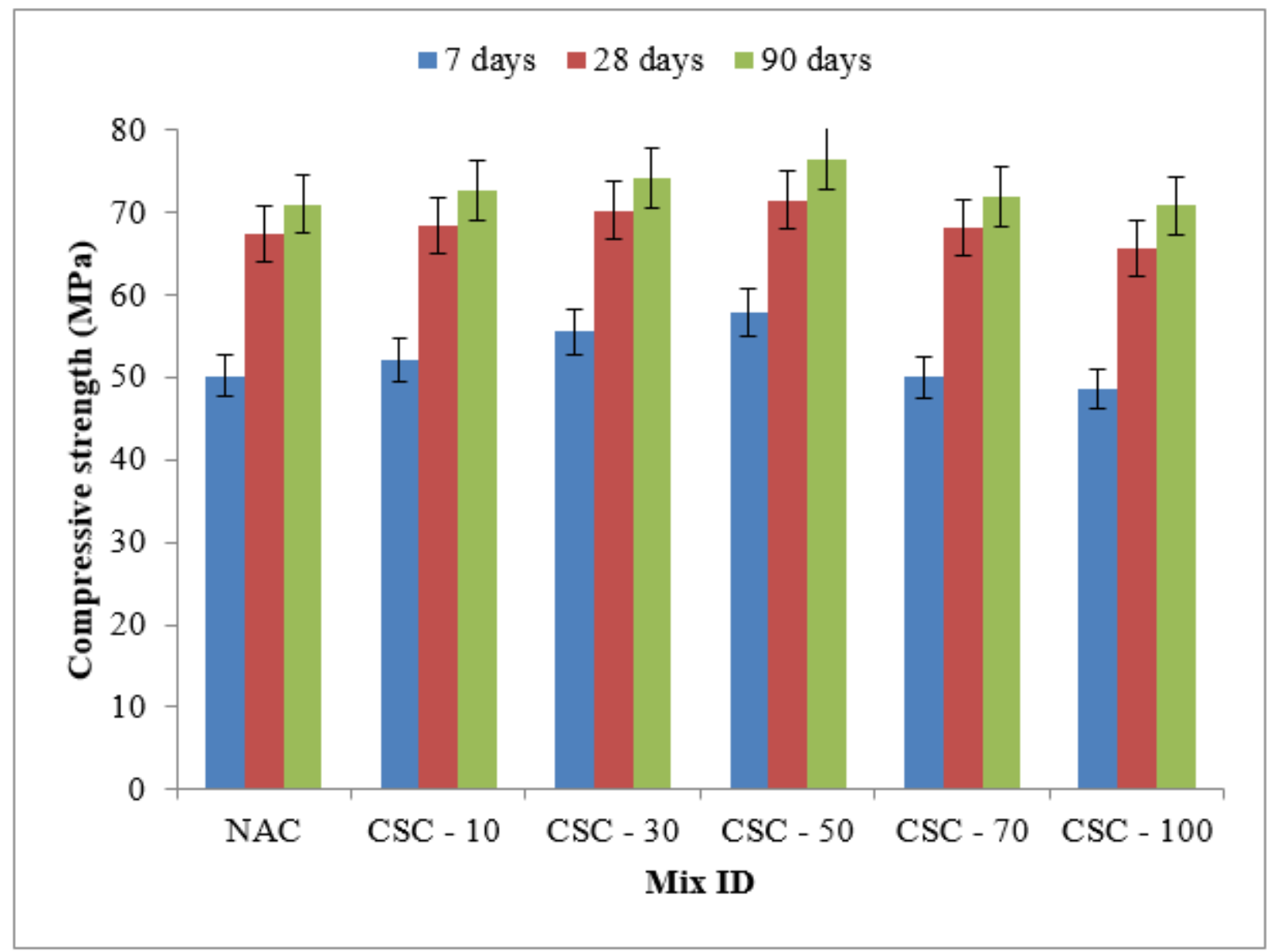

Figure 7

Compressive strength of the concrete mixes 


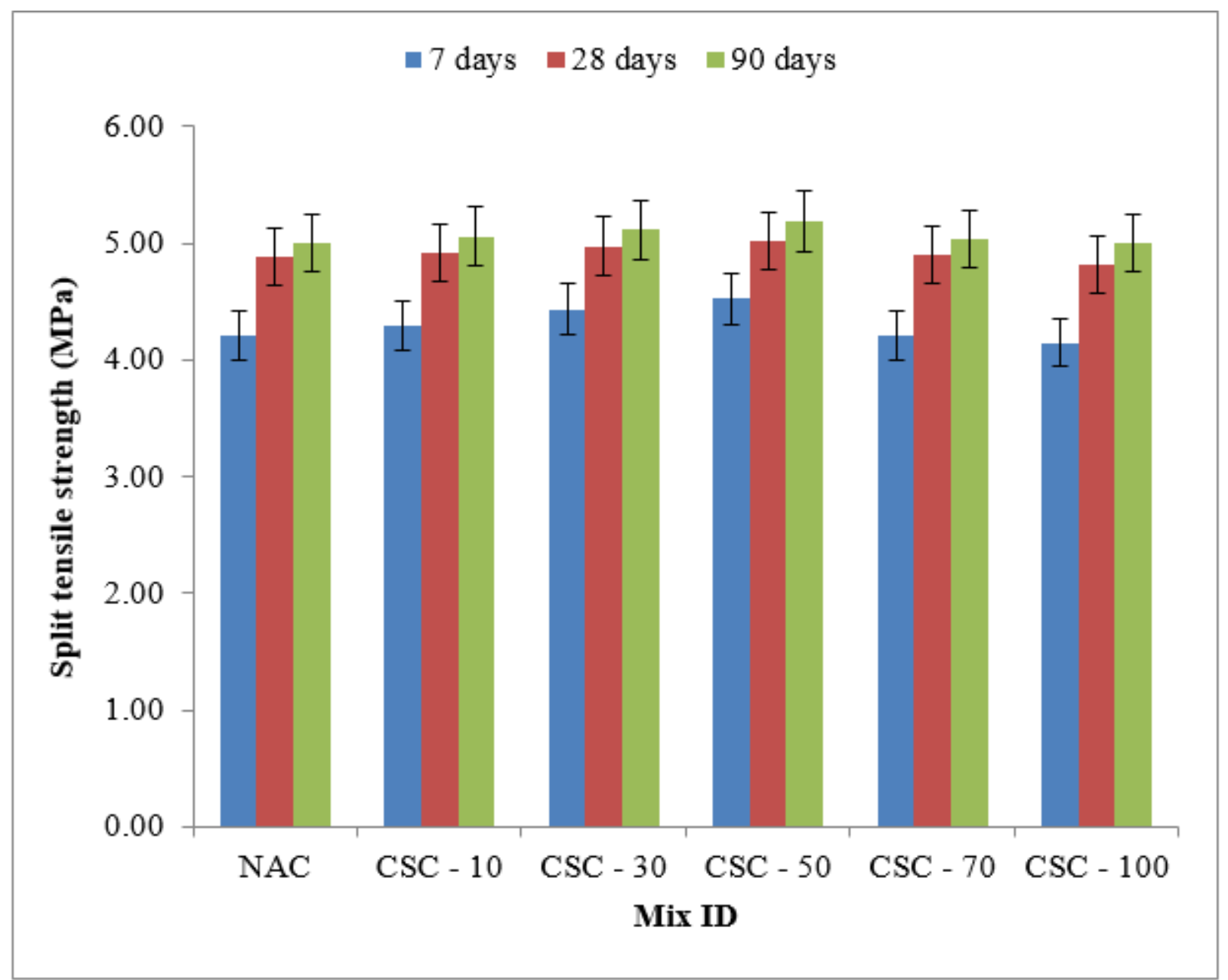

Figure 8

Split tensile strength of concrete mixes 


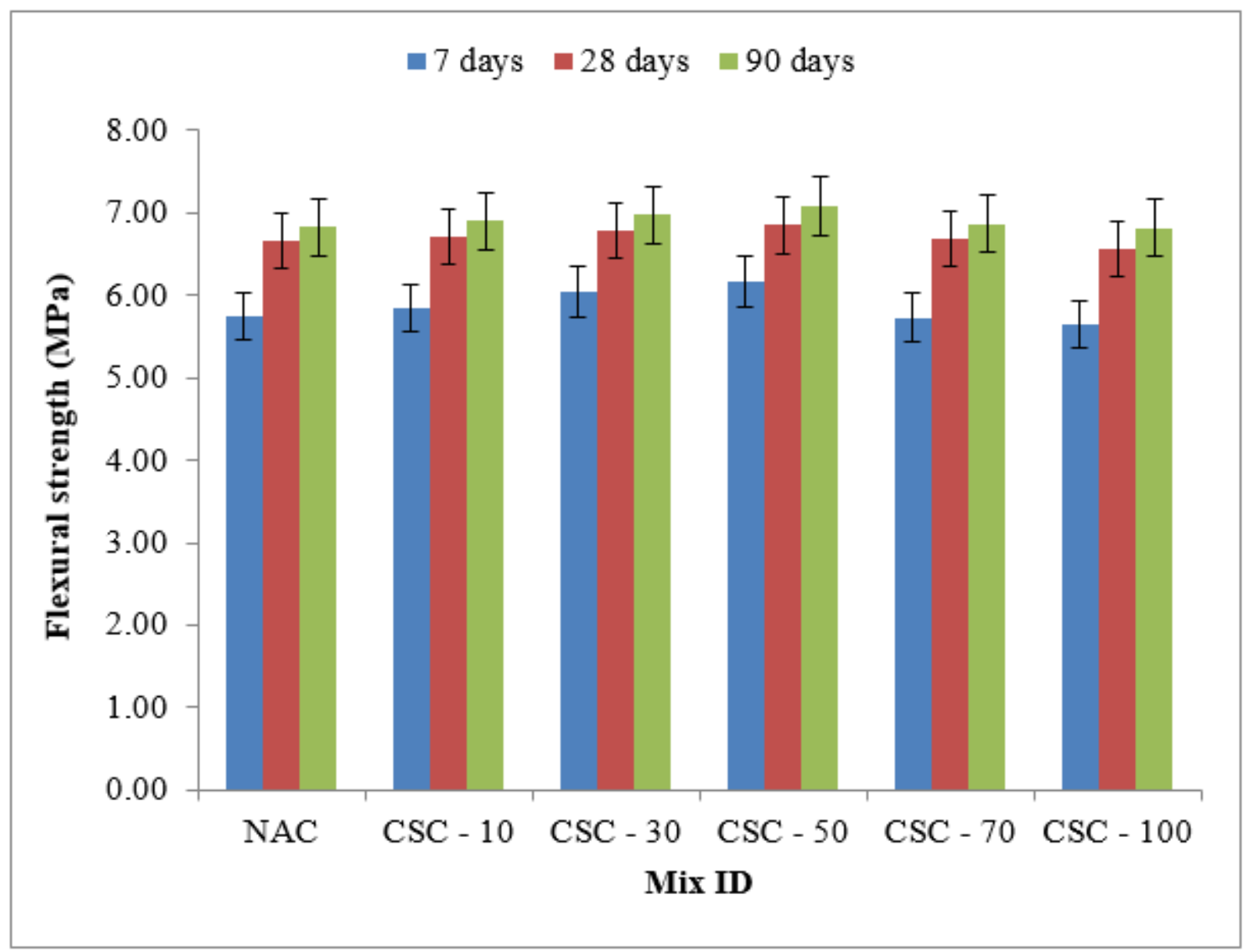

\section{Figure 9}

Flexural strength of concrete mixes

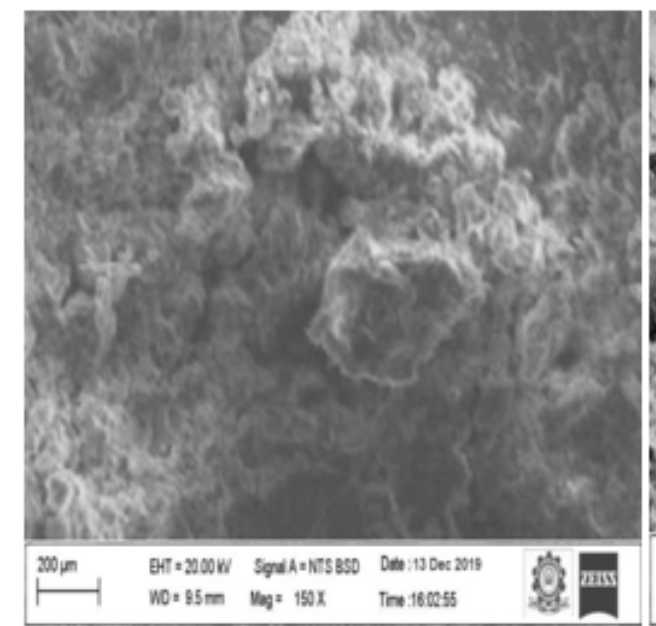

(a)

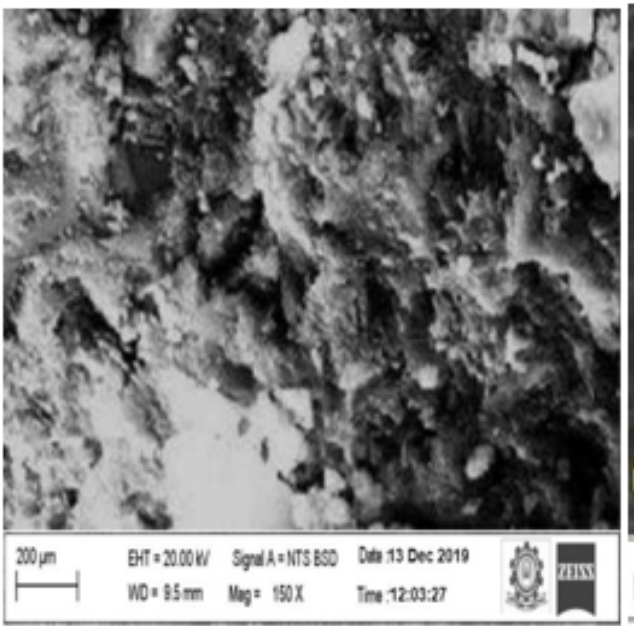

(b)

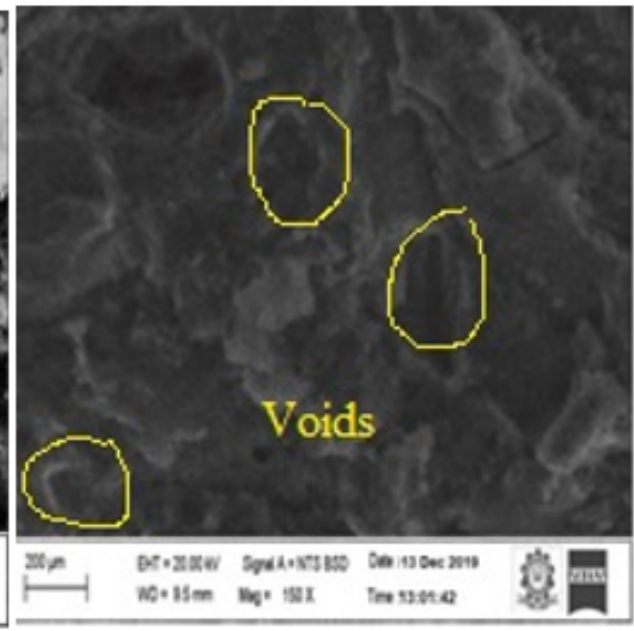

(c)

Figure 10

SEM images of HSC mix (a) NAC (b) CSC - 50 (c) CSC - 100 